\title{
TRICHOMONAS VAGINALIS INFESTATION IN MALE SUBJECTS
}

By WILLIAM GLEN LISTON, C.I.E., M.D., F.R.C.P.(Edin.) and ROBERT LEES, M.D., F.R.C.P.(Edin.)

[From the Laboratory of the Royal College of Physicians, Edinburgh]

\section{INTRODUCTION}

Trichomonas vaginalis infestation in females; some points of importance connected with the growth of the parasites in the vagina and their invasion of other parts of the body.

THE parasite Trichomonas vaginalis was discovered by Donné in I836, in the vaginæ of certain women suffering from leucorrhœa. Our knowledge of the parasite has been extended considerably since that time, especially in recent years. As long ago as 1865 this parasite was found in the vaginæ of as many as 37 out of 200 pregnant women examined by Kolliker and Scanzoni. The infestation of females by this parasite was known thus early to be widespread. Kolliker.and Scanzoni noticed that although the organism might be present abundantly in the vagina it was never found in the cervix.

While the presence of Trichomonas vaginalis in the vagina of a woman is generally associated with clinical symptoms, (an abundant greenish-yellow discharge which causes pain and irritation and a burning sensation about the external genitalia and thighs), some women may be infested, but unaware of their state. This has led to the view that the organism has no pathogenic properties but is a saprophyte. It has been suggested, also, that the absence of symptoms in certain cases may be attributed to the development of immunity, or that there is lacking in those patients without symptoms some additional element which, if present, would initiate symptoms. Hesseltine (I933), Curtis (I9I4), Allen, Jensen and Wood (I935), for example suggest that this additional factor is most probably a streptococcus. They believe that a 


\section{TRICHOMONAS VAGINALIS INFESTATION}

symbiotic union of a streptococcus and Trichomonas vaginalis is necessary for the production of symptoms. Liston and Liston (I939), on the other hand, have suggested that a suitable $p \mathrm{H}$ of the vaginal contents is important for the free development of Trichomonas vaginalis. Clinical symptoms, in their view, only appear when the parasites have established themselves and are multiplying freely. For this reason the $p \mathrm{H}$ reaction of the vagina is closely related to the development of symptoms. The optimum $p \mathrm{H}$ for the multiplication of Trichomonas vaginalis ranges around a $p \mathrm{H}$ of 6 . This work has been further elaborated by Liston associated with Cruickshank and will be published shortly. These workers found that Trichomonas vaginalis became less and less capable of developing in the vagina, as the reaction of the vagina became more acid or more alkaline than a $p \mathrm{H}$ of 6 . When, for example, the vaginal contents attained a $p \mathrm{H}$ of between 4 and 5 (this is the normal reaction in a healthy adult) Trichomonas vaginalis is very rarely found. The organism cannot thrive in these circumstances. Again when the $p \mathrm{H}$ of the vaginal contents lies between 7 and 8 (a condition found in children and in certain old persons, as well as in certain abnormal states), Trichomonas vaginalis does not then develop in the vagina. Similarly, the exacerbations of symptoms immediately before or after the menstrual period in longstanding cases of trichomonas vaginitis can be explained on the ground of changes in the $p \mathrm{H}$ reaction of the vaginal contents that take place at that time. The observation of Kolliker and Scanzoni that the cervix is seldom invaded by Trichomonas vaginalis is explained on the ground that the cervical secretion in normal circumstances is relatively alkaline when compared with the contents of the vagina. Trichomonas vaginalis therefore, in normal circumstances, cannot multiply there.

On the other hand the urethra is very often invaded by Trichomonas vaginalis. Here the $p \mathrm{H}$ reaction lies in the neighbourhood of 6 , so that symptoms of dysuria and frequency are common in association with trichomonas vaginitis. By the urethral route Trichomonas vaginalis may reach the bladder or even the kidneys. An example is reported by Lewis and Carroll (I928). The patient complained that she had been confined to bed for three weeks suffering from fever, chills and con- 


\section{BRITISH JOURNAL OF VENEREAL DISEASES}

stant pain on the left side radiating down the groin and thigh. These symptoms led the authors to suspect pyelitis, but to their surprise the urine was clear. X-rays and pyelograms failed to reveal any stones, stricture, or destruction of the renal pelvis. Cystoscopic examination revealed a reddened bladder mucous membrane. A catheter passed up both ureters without obstruction. The segregated urines from each kidney showed only a few pus cells and a few red blood cells. Lewis and Carroll considered that the explanation of the urinary symptoms was uncertain. McKinney, who performed the laboratory work in their office, centrifuged the urine collected from each kidney and examined the sediment microscopically. He drew their attention to a motile parasitic organism about five times the size of a red blood cell. This parasite, they learned, was Trichomonas vaginalis. Thereafter they had no difficulty in demonstrating its presence in the urine as well as in the vaginal secretion. They add that after a week's treatment by lavage of each kidney pelvis with 2 per cent. mercurochrome solution and daily bladder irrigation of $\mathrm{I}$ in $\mathrm{I}, 000$ silver nitrate solution the urine showed dead organisms, and later-the absence of organisms, although trichomonas still persisted in the vagina. Simultaneously with the destruction of the organisms in the urinary tract the symptoms of the patient subsided.

Discussing the pathogenicity of Trichomonas vaginalis they quote a number of opinions for and against its pathogenic properties. Their own conclusion is as follows - "The definite symptom complex presented in our patient and the recovery from symptoms coincident with the destruction of the organisms leads us to believe that this organism when found in the urinary tract is pathogenic."

Another case is reported by Visher (I929). A married woman, aged 32, childless, entered hospital complaining of frequent painful micturition and pain in the region of the right kidney, chills, high fever and prostration. Previous health had been good, but she suffered from an irritating vaginal discharge and dysmenorrhœe, both of which had been present for many years. Examination disclosed extreme tenderness over the right kidney. Numerous pus cells, much albumin and some casts were present in the urine. The diagnosis arrived at was acute 36 


\section{TRICHOMONAS VAGINALIS INFESTATION}

pyelitis and treatment by lavage was decided upon. A catheter passed into the right kidney delivered urine containing many pus cells and numerous trichomonas. The catheter was left in position and the renal pelvis was irrigated. The patient had no more chills, her fever subsided and she improved rapidly but symptoms of cystitis continued. Nine days after admission to hospital there was some inflammation about the neck of the bladder, but no redness around the ureteral orifices. Bladder urine obtained through a cystoscope showed no albumin or casts, but contained a few pus cells and numerous flagellates, recognised as Trichomonas vaginalis. The right kidney remained tender for about a month. Cystitis recurred four months after she left hospital and at this time trichomonas were again found in the bladder. Her condition improved gradually under treatment.

Other cases of infection of the bladder in females by Trichomonas vaginalis have been reported by Nitschke (1936), and it seems that the condition is more common than is usually recognised.

\section{ReView of the Literature on Trichomonas VAGINALIS INFECTION IN MALES}

In this paper we are mainly concerned with Trichomonas vaginalis infestation in males.

A masterly paper published by George Dock in I896, one of the earliest on the subject, reviews the knowledge of the flagellates parasitic in men available at that time. He states that undoubtedly the first case of trichomonas infestation of the urinary tract of a male patient was published by Marchand in I894. A man aged 6o had suffered from a fistula in the perineum for I7 years following on suppuration in the pelvis. The condition was regarded as tubercular. Pus suddenly appeared in the urine without symptoms of cystitis so that rupture into the bladder of an abscess in the pelvis was suspected. The general condition of the patient improved but the urine remained turbid; it was acid and albuminous with a copious dirty yellow sediment containing numerous whitish particles. On microscopical examination these were found to be made up of epithelial cells, hyaline casts, and red blood cells, and among these cells flagellates were noticed. The urine also contained numerous bacilli and 


\section{BRITISH JOURNAL OF VENEREAL DISEASES}

cocci. Marchand concluded, as a result of comparative examinations of this flagellate parasite from the bladder and flagellates found in the vagina in certain females, that there was at least a great resemblance if not identity between them. He thought that the parasites from the bladder were more hyaline, less plainly vacuolated, smaller and more amoboid, than the trichomonas from the vagina, which he knew were Trichomonas vaginalis. He thought that these differences might depend on the character of the medium in which the different organisms lived.

About the same time K. Miura (1894) of Tokio, met with a case in a Japanese man aged 52. The freshly passed urine, of a yellow colour and acid reaction, contained thread like particles which consisted of round cells, colourless mucus, epithelial ceils and flagellates. Most of the particles were passed with the first part of the urine and a self-retaining catheter demonstrated that the organisms came from the urethra and not the bladder.

The next case to be recorded is that described by Dock (I896) himself. He made a very careful study of this case and particularly of the flagellate parasite he found in the urine. A young man, aged 27, had suffered from painful and difficult micturition during convalescence from an attack of pneumonia. After two days blood appeared in the urine. The bleeding soon stopped but the difficulty in micturition continued for a time. During the attack the patient had to urinate every two hours. There was then pain in the left lumbar region and in the right groin. At the end of micturition whitish particles were passed. The patient, who denied coitus or any possibility of venereal disease, had consulted many physicians who diagnosed "gleet" and advised instrumental treatment. But as the patient knew that he could not have gleet, he always declined. Dock, who seems to have been less drastic in his method of treatment, found that the patient could pass urine in a full stream. The urine was yellow in colour, acid in reaction, and was free from albumin and sugar; the particles present were found to be made up of pus, epithelium and numerous flagellates. These latter were studied in minute detail. There can be no doubt from the drawings and excellent description given in the paper that Dock was dealing with a Trichomonas vaginalis infection of the 


\section{TRICHOMONAS VAGINALIS INFESTATION}

urinary tract in this young man. How he had acquired infection and in what part of the urinary tract the lesion was located remains obscure.

In I924 Katsunuma reported a case of Trichomonas vaginalis infection in a boy aged 3 years who might have been infected from a female attendant. The flagellates in this case were multiplying in the preputial sac where they caused redness and odema.

Dastidar (1925) reported trichomonas in four cases during routine examination of some thousand specimens of urine derived from both sexes. Three of the cases were males, and one a female. In each case the urine was acid, contained a few pus cells, and numerous trichomonas. The urines were freshly collected and there was no possibility of contamination from the bowel or other source. He concludes that the trichomonas may cause a mild urethritis attended with smarting and burning on micturition, but that this urethritis cures itself on the disappearance of the trichomonas.

In 1927 Capek, quoted by Grimm (I930), observed two cases of trichomonas urethritis during the course of one year. The one was a married man, aged 40, who passed turbid bloody urine. In his urethra numerous Trichomonas vaginalis were found. This man's wife suffered from trichomonas vaginitis. The other case was a man of 27 who suffered from an abundant purulent bloodstained exudate from the urethra in which Trichomonas vaginalis were abundantly present ; this patient suffered from acute epididymitis.

Riba and Perry (I929) reported two cases of Trichomonas vaginalis infection in males. One was a man aged 28 who complained of urethral discharge and nocturnal frequency especially following intercourse. Physical examination revealed a prostate of approximately normal size, but slightly irregular. Trichomonas were found in a direct smear of the prostatic secretion. The other case was a coloured man aged $6 \mathrm{I}$ who had diurnal and nocturnal frequency of micturition with slight burning. A week later he developed a purulent discharge. The prostatic secretion contained many motile trichomonas and a large number of pus cells.

Grimm (I930) described an additional five cases of trichomonas infection in males. His first case was a married man with a urethral discharge which had been 


\section{BRITISH JOURNAL OF VENEREAL DISEASES}

treated without improvement. A direct smear from the urethra showed many trichomonas but none were found in the prostatic fluid. His wife suffered from trichomonas vaginitis.

The second case was a single man aged 25 who had coitus four months before. He first noticed urethral discharge two weeks after coitus. Trichomonas vaginalis was detected in fresh films from the urethra.

The third case was a single man aged 42 who gave a history of gonorrhœea three years previously. He had been treated for non-specific urethritis for three months.

The fourth case was a single man aged 25 who had suffered from gonorrhœal urethritis eighteen months previously. For a month he had complained of burning at the meatus with some purulent discharge.

The fifth case was an unmarried man, 29 years old. He had suffered from gonorrhœa one year before. He had intercourse three weeks prior to the development of the urethral discharge which was associated with burning during and after micturition. Trichomonas were demonstrated in the fresh film, as in the other cases.

Rosenthal (I93I) reported an interesting case of urinary infection with Trichomonas vaginalis in a man aged 72. Following on operation for gallstones the patient developed an acute attack of pyelitis. Rectal examination revealed a moderate degree of enlargement of the prostate but no tenderness. The acid urine contained pus cells, coliform organisms and Trichomonas vaginalis.

Recalling our observations on the $p \mathrm{H}$ requirements of Trichomonas vaginalis it is interesting to note in this case that when the urine was rendered alkaline the trichomonas disappeared and the symptoms subsided. There was no relapse later when the urine became acid again.

In I933 Stuhler reported that out of 32,000 examinations of prostatic secretions at the Mayo Clinic, Trichomonas vaginalis was found sixteen times. The technique of the examination is not described, and his findings are thus open to criticism. He referred, in particular, to the case of a man 52 years old who complained of pain low in the back and in the hips. The urine was negative except for an occasional pus cell and the general examination was negative. Frequency of micturition amounted 


\section{TRICHOMONAS VAGINALIS INFESTATION}

to six times per diem and twice at night. There was a history of gonorrhœa twenty years before. At the first examination the prostatic fluid contained many trichomonas and at subsequent examinations a slight urethral discharge was noted.

Allen, Jensen and Wood (I935) found Trichomonas vaginalis in fresh films of the prostatic fluids of six husbands whose respective wives suffered from trichomonas vaginitis. They stress the danger of re-infection of wives under treatment by their husbands who may harbour this parasite. They failed to find infection in the prostatic fluids of three other husbands although their wives also suffered from trichomonas vaginitis. They give details of one resistant case of trichomonas vaginitis who they thought was re-infected by her husband. She had been under treatment and apparently had been cured. She went from home on a holiday remaining free during this period. Seven days after returning from this holiday she came again with acute symptoms and five days later her husband appeared complaining of dysuria and slight urethral discharge. The prostatic and vaginal fluids contained swarms of trichomonas.

Similar observations were made by Cornell and Riba (I936) who state that in 7 years they came across 30 cases of Trichomonas vaginalis infection in men. Twenty-five of the men were married. They believed that trichomonas infection in the male is acquired solely through sexual contact. They give details of three cases only but add that usually symptoms of chronic prostatitis are present and that a urethral discharge is found when the urethra is involved. Five of their cases of prostato-vesiculitis were complicated by multiple strictures of the anterior urethra and these cases occurred in the married group. The wives of three of these five cases who were examined harboured Trichomonas vaginalis.

Drummond (I936) made a very similar investigation. He obtained the names of nine women who suffered from trichomonas vaginitis and he persuaded the husbands of five of these women to be examined. Using cultural methods as well as direct films of fresh prostatic fluid he repeated the examinations on two or three occasions in some of the cases. He believed that he was successful in demonstrating the presence of Trichomonas vaginalis in the prostatic fluid in four out of the five cases. 


\section{BRITISH JOURNAL OF VENEREAL DISEASES}

It is important to note that none of the men presented any symptoms. Trichomonas were detected in only one case in the primary direct film from the urethra. Even if due allowance is made for the remarkable care exhibited in carrying out these examinations, Drummond's successful results in demonstrating Trichomonas vaginalis in four out of five men without symptoms, contrasts with that of other workers who have not been so successful in their examinations. His findings undoubtedly give an exaggerated importance to trichomonas infestation in males.

Karnaky (I938) states that he found 38 infected among I5o husbands whose respective wives suffered from trichomonas vaginitis. He found the trichomonas in his cases either in the urethra, in the prostate, or under the prepuce. He advised the making of three smears, one from the urethra before and after prostatic massage and one from under the prepuce. He says that Trichomonas vaginalis in the men examined caused itching of the glans penis in some cases; some of the cases had a whitish morning drip, but most of the men had no symptoms. A few had an acute urethritis. He adds that if Trichomonas vaginalis infections are left untreated and if re-infection does not occur, the trichomonas usually die within two or three months.

The workers mentioned above have generally examined selected groups of men; they have not attempted to estimate the extent to which trichomonas infection may be found among men who are affected with urethral symptoms. Nitschke (I936) tries to do this to some extent for he records that he met with five cases of Trichomonas vaginalis infection among forty cases of non-specific urethritis examined by him during a period of eighteen months. In all the cases he found that the wives or consorts, associated with the infected males, suffered from trichomonas vaginitis.

Here we may mention that we have not seen a single paper on this subject in a medical journal published in Great Britain and this has been our reason for referring in greater detail, than might otherwise have been necessary, to the papers published in America, Germany, France, India and Australia.

The object of our investigation was to determine to what extent Trichomonas vaginalis infestation was present among a consecutive series of 400 men attending a 


\section{TRICHOMONAS VAGINALIS INFESTATION}

Venereal Diseases Clinic. We excluded from the survey those who were found to be suffering from syphilitic lesions. A certain number of men who attended after exposure to possible infection had no symptoms but were anxious to know whether they had been infected. These cases were not numerous but they have been included. We hoped also to make a study of such cases of trichomonas infestation in male subjects as came under our observation with a view to determining the extent and severity of the lesions produced by these organisms.

\section{Methods of Recognising the Presence of Trichomonas in Purulent Discharges}

There are three ways by which trichomonas can be demonstrated.

(i) Microscopical examination of moist films. This was the method usually adopted by the workers we have reviewed.

(ii) Microscopical examination of cultures. This method was adopted by Drummond for example-in addition to the first method.

(iii) The microscopical examination of suitably prepared and stained films. We used the method introduced by Liston and Liston.

These authors have described in detail the various methods of detecting trichomonas and their paper on the subject should be consulted. Here it will suffice to say that one of us (W. G. L.) has had an extensive experience of the use of the three methods and has come to rely more and more exclusively on the third method. The great advantage is that films can be made in the clinic, without disturbing the ordinary routine and can be examined at leisure.

In the early stages of our investigation we used the second method also but we found that these cultures often failed to demonstrate trichomonas when they were detected in suitably stained films, so that towards the end of our investigations cultures were abandoned. In the end we relied on the examination of two films from each case. One film was stained by Gram's method to determine the presence or absence of gonococci and other organisms; the other was treated with Leishman's stain and examined for trichomonas. 
We may here emphasise some points in securing wellstained films. The first essential is to use thoroughly clean slides. If the slides are heated to a temperature a little below the boiling point of water at the time the films are made better fixed preparations can be obtained. We have placed the slides on the top of an instrument steriliser immediately before they were used, or immediately after the films have been spread in order to secure a rapidly dried film. The films are spread by means of a platinum loop or by using a cottonwool swab, or by dipping the edge of a piece of cigarette paper in the discharge and drawing it over the surface of the slide. The film should be spread very gently and not rubbed over the surface. When the film is dry one cubic centimetre of a reputable brand of Leishman's stain is allowed to act upon it for one minute. Then about one and a half cubic centimetres of distilled water is added drop by drop to the stain on the slide, and thoroughly mixed. The diluted stain remains on from ten to fifteen minutes and is then washed off with a little distilled water. Some fresh distilled water is left in contact with the film for a few minutes to extract any excess of stain. The slide is then allowed to dry in the air.

A drop of neutral mounting medium is then placed upon it followed by a coverglass. It is then ready to be examined under the microscope. This stain is conveniently put up in the form of small tablets * containing 0.0I5 grammes of the stain and are dissolved in Io cubic centimetres of pure methyl alcohol. The stain improves with keeping.

Fig. I. is a drawing from a film magnified 300 diameters, prepared from the secretion beneath a prepuce infested with Trichomonas vaginalis. It shows the presence of a number of trichomonas easily recognised by their light-blue colour and oval red nucleus. The drawing was made from a crudely fixed film prepared simply by allowing some of the discharge spread upon a glass slide to dry in the air. The flagella, axostyle and undulating membrane are not revealed, yet the trichomonas are easily recognised and could only be confused by a careless observer with an epithelial cell. The nuclear structure of a trichomonas is very different from that of an epithelial cell.

* Obtainable from G. T. Gurr, 136 New King's Rd., London, S.W. 6. 


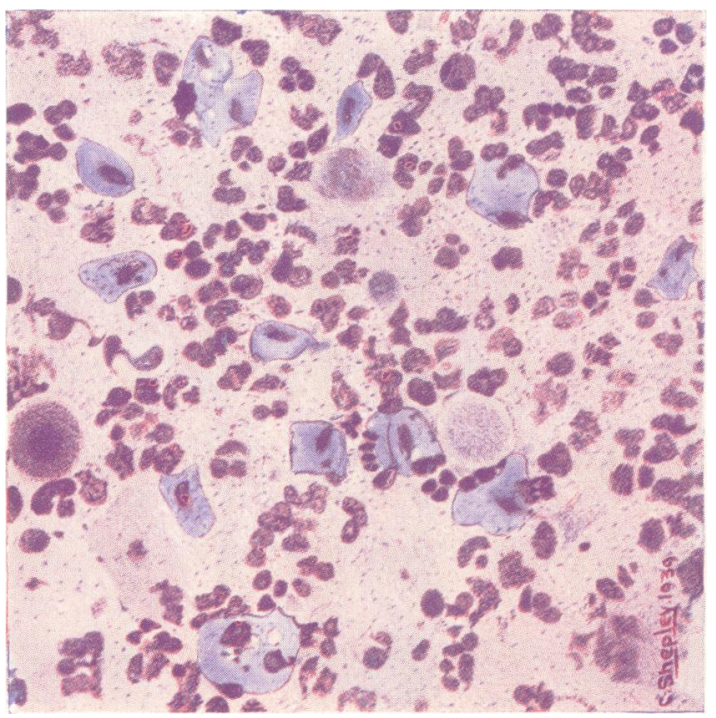

है
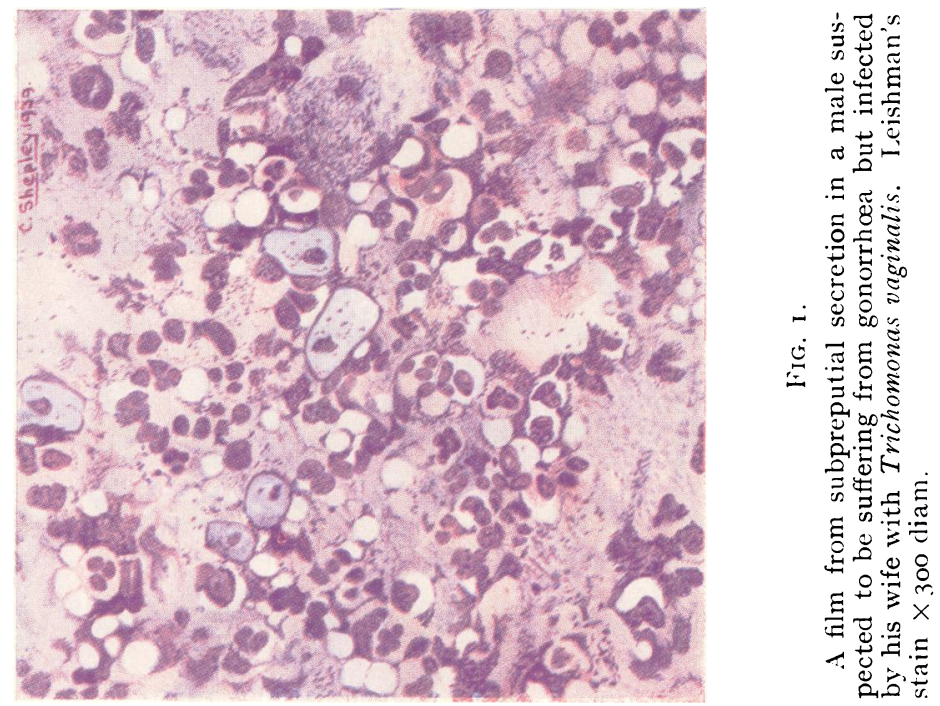


\section{TRICHOMONAS VAGINALIS INFESTATION}

Fig. 2. is a similarly crudely fixed film from a case of trichomonas vaginitis stained in a similar way.

\section{Clinical Material and Findings}

The results of the examination of 400 consecutive cases attending a Venereal Diseases Clinic for male patients are displayed in Table I. Cases of syphilis only are excluded. The examinations were interrupted on two or three occasions when one or other of the authors was on holiday, but the work was resumed on return to duty.

\section{TABLE I.-Analysis of 400 Consecutive Cases (exsluding} Syphilis) attending the V.D. Department of the Royal Infirmary, Edinburgh

Gonorrhœa · $\quad . \quad$. $\quad . \quad$. $\quad .263$

Urethritis (non-gonococcal) . . . 78

Trichomonas urethritis (including one case also suffering from gonorrhœa) . . I6

Balanitis . . . . . . II

Prostatic abscess . . . . . I

Chronic prostatitis . $\quad . \quad . \quad . \quad . \quad . \quad 2$

Chronic vesiculitis . . . . . I I

Cowper's Gland abscess . . . . . I

Acute epididymitis (non-gonococcal) . I

Chronic epididymitis (non-gonococcal) . 3

Cystitis . . . . . . . . I

No evidence of venereal disease $\quad . \quad$. 22

$$
\text { Total . . . . . } 400
$$

Gonococci were present in 264 cases (66 per cent.). Trichomonas vaginalis was found in $\mathrm{I} 6$ cases (4 per cent.) in this series. One patient had both gonococci and Trichomonas vaginalis present in the urethra.

There were 78 cases of urethritis, in which gonorrhœa had been excluded; Trichomonas vaginalis were not found, and the cause of the urethritis could not be stated precisely. In all there were I05 cases with disease of the genito-urinary system, excluding gonorrhœa, and I6 of these cases ( 6 per cent.) were caused by Trichomonas vaginalis. 


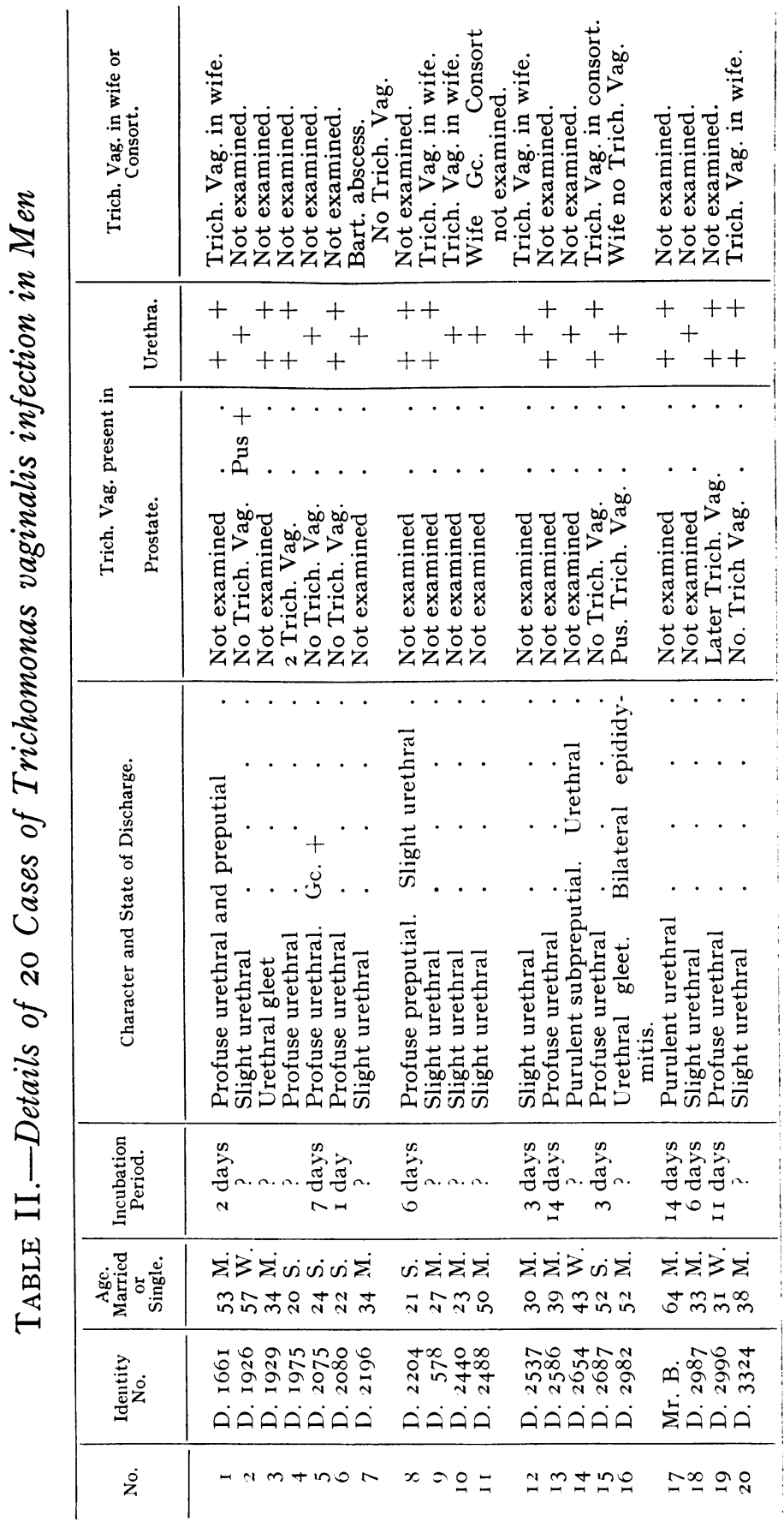




\section{TRICHOMONAS VAGINALIS INFESTATION}

\section{An Examination of 20 Cases of Trichomonas VAGINALIS INFESTATION IN MEN}

\section{Infestation of Subpreputial Sac}

This area presents a moist surface, often bathed with urine, and if the hydrogen ion concentration approximates to a $p \mathrm{H} 6$ the development of Trichomonas vaginalis is favoured. The subpreputial sac was infested in 5 of our cases-Nos. I, 6, 7, 8 and I4. Some of them also had infestation of the anterior urethra. They were all readily cured when the preputial sac was washed out or when circumcision was performed.

Case I.-Age 53, married many years, had not developed a discharge previously though his wife had a chronic form of trichomonas vaginitis.

Case 6.-Age 22, single, had coitus with one girl on two occasions, and rapidly developed symptoms of urethritis.

Both these cases showed some anterior urethritis while cases 7 and 8 showed little evidence that the urethra was invaded.

Case 7 was a married man who had previously suffered from preputial discharge. He had not had extra-marital contact, and his wife showed no evidence of trichomonas vaginitis, but she had suffered from a Bartholinian abscess which had been treated with antiseptics shortly before our examination.

\section{Infestation of the Anterior Urethra}

Our cases Nos. 3, I0, II, I2, I3, I5, I7, I8 and 20 suffered from symptoms indicating infestation of the anterior urethra. Six of the cases were very mild.

Case 3 was at first regarded as that of a husband who, having been exposed to infection, was unduly anxious about a slight urethral irritation and trivial discharge. A film of the urethral secretion showed, however, numerous pus cells and trichomonas. In a field under $\frac{1}{6}{ }^{\prime \prime}$ objective as many as 4 trichomonas could be seen. The consort of this man was unknown. He recovered rapidly and spontaneously and he was discharged as cured after three months observation.

Case Io was referred to the Clinic by a lady medical 
officer who was treating his wife for gonorrhœa. Further investigation of this wife showed that in fact she did not suffer from gonorrhœa but from trichomonas vaginitis. The husband's urethral film contained a few pus cells and trichomonas.

Case II was sent to the Clinic as his wife was suffering from gonorrhœa, but she showed no evidence of Trichomonas vaginalis infestation. The urethral films from the husband contained trichomonas but no gonococci. Further inquiries revealed that the man was not cohabiting with his wife but with another woman; while his wife was living apart from her husband and with another man. These consorts could not be persuaded to come for examination.

Case I2 came to the Clinic because his wife was being treated for trichomonas vaginitis in the female V. D. Department. He had a very mild trichomonas urethritis which cleared up rapidly.

Case 15 , by contrast, suffered from a very profuse greenish discharge which closely resembled that found in acute gonorrhœa. This case is interesting, in that he was an unmarried man, who had been "keeping company" with a young girl for some time. He had coitus with her on two occasions and within three days of the last contact developed the discharge. The girl was unaware that she suffered from any unusual discharge but on examination she was found to be suffering from chronic trichomonas vaginitis.

Case I7 was another case who had exposed himself to infection three weeks before the symptoms developed. He suffered from a discharge which so closely resembled a gonorrhœal discharge that he was treated, pending bacteriological investigation, with one irrigation of a I in 10,000 potassium permanganate and I9 tablets of “M. \& B. 693." Further examinations were made and Trichomonas vaginalis were detected, but no other organisms. An alkaline diuretic mixture was prescribed and he improved rapidly.

Case I 8 suffered from a mild anterior urethritis. $\mathrm{He}$ had been exposed on a number of previous occasions to infection from the same woman, and only developed discharge six days after the last exposure. He recovered rapidly and spontaneously, and has remained well for over three months. Urethroscopic examination showed 48 


\section{TRICHOMONAS VAGINALIS INFESTATION}

slight congestion of the anterior urethra, but no other change.

Case 20. A married man, aged 38 , had symptoms of urethral irritation for two months which were not related to micturition. There was very little discharge and the urine appeared clear and free from pus and debris. His symptoms were not accentuated by coitus. He stated that he had never exposed himself to infection but on two previous occasions he had been treated in our Clinic for non-gonococcal urethritis. His wife had no complaints and thought that the patient was making a needless fuss.

Urethral films contained numerous pus cells and Trichomonas vaginalis but no other organisms. The blood gave a negative Wassermann reaction and a negative gonococcus complement fixation test.

On urethroscopic examination the floor of the penile urethra was slightly congested, lacked lustre, and appeared granular. The mucosa was elastic, and the mucous glands did not appear abnormal. Examination of prostatic secretion showed no trichomonas. The urine $p \mathrm{H}$ was $6 \cdot \mathrm{I} 8$.

Examination of his wife revealed chronic vaginitis with numerous Trichomonas vaginalis. She had previously attended a gynæcologist but the infestation had not been recognised.

\section{Infestation of Posterior Urethra}

The trichomonas infestation in cases Nos. 5 and 9 seemed to have extended to the posterior part of the urethra.

Case 5 was a sailor who had exposed himself to venereal infection ten days previously. Symptoms had been present for three days. He suffered from a profuse purulent discharge, in which both gonococci and trichomonas were found. This was the only case among the twenty examined in which both organisms were present.

Case 9 is of special interest. Three weeks after marriage a purulent urethral discharge appeared. Although no gonococci were found treatment with irrigations and sulphanilamide was instituted. Frequent relapses occurred during the next few months and urethroscopy, about nine months from the commencement, showed a 
small scarred area in the deeper part of the urethra. There was no congestion and the urethra dilated well. No infected Littre glands were seen but they were all patulous and secreting clear mucus.

A diagnosis was made of simple non-gonococcal urethritis. About two months later a slight mucopurulent discharge appeared, also slight pain in the urethra and pyuria.

His wife, who had previously refused examination, was now found to be suffering from trichomonas vaginitis and was treated. The husband was given instillations of argyrol, irrigations with potassium permanganate and later instillations of a suspension of Stovarsol. The symptoms disappeared rapidly and both patients have remained well for several months.

Case 4.-A young man attended a dance in a remote part of the country. He had intercourse with a girl, and two other companions also had connection with this girl. All three men developed a discharge within a few days. There was no male medical officer in this place, so he consulted a lady doctor who refused to examine him, but prescribed "white tablets" which caused him to be giddy and sick. The discharge continued. He had not been irrigated when we examined him rather more than a month after exposure to infection.

$\mathrm{He}$ was then found to be suffering from what appeared to be a typical gonorrhœal discharge. Films showed numerous pus cells and trichomonas but no gonococci. Gram-negative and Gram-positive bacilli and Grampositive cocci were also present. A smear after prostatic massage at this time showed the presence of two trichomonas. Under treatment he cleared up rapidly. Two months later, he got drunk and a slight discharge developed with a swelling of the right testicle. This was a hydrocele associated with a sub-acute epididymitis. He has been under observation for six months with no evidence of a recurrence.

Cases showing Extension of the Parasites to the Bladder, Seminal Vesicles or Prostate

Lastly there is a fifth group of cases which suggest that an extension of the trichomonas infestation had taken place to the prostate, seminal vesicles and possibly to the 


\section{TRICHOMONAS VAGINALIS INFESTATION}

bladder and kidneys. The symptoms and signs in these cases are more severe. One of these cases was associated with stricture of the urethra.

Case 2.-A widower, aged 57, who had suffered from gonorrhœa 25 years ago, and who had not had coitus for several years, attended with a left epididymitis of 5 weeks duration on March 3, I939. He had no pain on micturition but frequency was severe-almost hourly during the day and twice at night. In I938 he had been treated in another hospital for stricture of the urethra.

On examination there was slight muco-purulent urethral discharge. The urine contained much pus. Per rectum the prostate showed enlargement of both lobes, but no undue tenderness. The urethral film contained pus cells and a few trichomonas but no organisms. There was no evidence of gonorrhœa or syphilis.

On 4th April, I939, the left epididymis became acutely inflamed but subsided in a few days, to relapse again on I7th September with recrudescence of the discharge and pyuria. A film of prostatic secretion on I7th February, I939, showed numerous pus cells but no trichomonas were found.

Case I6.-Aged 52-married for $\mathrm{I} 3$ years. He was not aware that he suffered from a urethral discharge and denied extra marital intercourse. He had a bubo twenty years ago which was untreated. Two years ago he suffered from a swelling of the left testicle. The epididymitis recurred two weeks ago and there was slight scalding on micturition; the urinary stream was satisfactory. He has recently suffered from what he regarded as malaria-i.e. rigors and fever. With these attacks there was a slightly increased frequency of micturition. Both lobes of the prostate were enlarged and irregular in outline, and pressure caused acute pain. Very slight gleet of muco-purulent character was present. Both epididymes were nodular, especially the right, the upper poles being particularly affected ; they were slightly tender but not adherent to the skin.

The acid urine contained a number of pus cells. The $p \mathrm{H}$ estimated by "the capillator method" gave the following results:-4-II indicator between 5 and 6 . Methyl-red indicator $5 \cdot 6$. Brom-cresol-purple indicator 5.5, and electrometrically, using a glass electrode, 5.98; 
a $p \mathrm{H}$ in fact very suitable for the development of Trichomonas vaginalis.

The urethral films showed many pus cells, some epithelial cells and a number of trichomonas. A film of prostatic fluid showed many pus cells and two definite trichomonas were seen, and other less definite forms were noticed. This patient still showed the presence of Trichomonas vaginalis in urethral smears some months after the first examination.

Films and clinical examination of this man's wife failed to show any abnormality, or the presence of trichomonas in her vagina. How he had become infested with Trichomonas vaginalis is obscure.

Case I9.-A widower, aged 3I, who twelve days previously had had coitus with a prostitute, presented a discharge which had been noted for one day. He suffered from no pain on micturition, but there was a marked increase in frequency, hourly by day, but there was no frequency at night. He had previously suffered from non-gonorrhœal urethritis, been treated and discharged as cured. Examination revealed a profuse urethral discharge, with some redness and œedema around the urinary meatus. The inguinal glands were not enlarged. The first specimen of urine was very turbid with pus but the second was clear. There was no apparent abnormality of the prostate. The Wassermann reaction and gonococcus complement fixation test were negative. He was treated at first, empirically, with sulphapyridine, but there was no response. The urethral film, taken before treatment was begun, showed numerous pus cells, no gonococci or other organisms, but many Trichomonas vaginalis. Treatment with alkaline mixtures and instillation of the urethra with Io per cent. argyrol was ineffective. Eighteen days after the first examination there was evidence of spread to the posterior urethra, prostate and left epididymis. Four days later he suffered from acute prostatitis; the left lobe and the left seminal vesicle were enlarged and tender. There was an increase in the amount of the urethral discharge and pus in the urine. The lower.pole of the left epididymis was slightly enlarged and tender. The prostatic secretion contained Trichomonas vaginalis. This condition cleared up rapidly thereafter and has remained quiet, with repeated negative smears, for two months. 


\section{TRICHOMONAS VAGINALIS INFESTATION}

\section{FURTHER Notes}

Two cases, No. 2I and No. 22, may be added to this list. Both were young men; each had had coitus with his fiancée about Io days before the onset of the symptoms. Both men suffered from acute anterior urethritis closely resembling acute gonorrhœa, but no organisms were found by examination of smears and cultures from the urethra. No Trichomonas vaginalis were found in these cases. In each case the man accused his fiancée of venereal infection, and when the girls were examined each was found to suffer from trichomonas vaginitis and from no other disease.

This group is of some importance as it indicates that Trichomonas vaginalis infestation of the male urethra may be more frequent than our figures indicate. A rapid spontaneous recovery occurs in the great majority of cases and unless several films are examined at the onset of the disease the true cause of the urethritis may escape recognition. The social difficulties arising from false accusations of veneral disease do not need further elaboration.

Certain observations regarding Trichomonas vaginalis infection in males noted during our investigations may be mentioned. The incubation period may be as short as one day, but often extends to I4 days. In some cases, as might be expected owing to the mild nature of the symptoms, the incubation period cannot be determined. I 4 of the 20 cases were married or widowers. Six of the 20 cases were over 50 years of age. On the whole, the older men appeared to suffer more than the younger.

\section{TREATMENT}

While the small number of cases and the short period of observation does not permit of conclusions regarding the results of treatment, the following observations are recorded.

I. Irrigation or instillation of the urethra with antiseptics is not curative, and frequently does harm.

2. A strongly alkaline urine inhibits the development of trichomonas, relieves symptoms, and may produce clinical cure. A permanent cure may be so produced. 


\section{BRITISH JOURNAL OF VENEREAL DISEASES}

3. Relapse is frequent, and is often precipitated by alcohol, coitus or irritating treatment.

4. Re-infection from an infected partner is common.

5. Prolonged observation is necessary.

6. Symptoms from infestation of the prostate may occur and recur at long intervals after the primary infestation.

\section{Conclusions}

I. Approximately 4 per cent. of all males attending a Venereal Diseases Clinic (excluding syphilitic cases) suffer from Trichomonas vaginalis infestation.

2. Approximately 16 per cent. of males suffering from " non-gonococcal urethritis" are cases of Trichomonas vaginalis infestation.

3. The disease is generally acquired by sexual intercourse with women suffering from trichomonas vaginitis.

4. Trichomonas vaginalis infestation of the urogenital tract in males is generally a trivial disease and in some cases will pass unnoticed. Very serious symptoms may develop when the parasite invades the prostate, seminal vesicles, epididymes and upper genito-urinary tract.

5. The severity of the disease may be graded according to the area infected with Trichomonas vaginalis-

(i) The preputial sac.

(ii) The anterior urethra.

(iii) The posterior urethra.

(iv) The prostate and seminal vesicles and epididymes.

(v) The whole urogenital tract.

The process of extension generally takes place slowly from the earlier sites to the later, but the invasion of the male urogenital tract by Trichomonas vaginalis may be cut short at any of the stages. When Trichomonas vaginalis reaches the prostate, however, eradication of the infestation becomes difficult, relapses are frequent and the disease often becomes chronic.

6. Invasion of the prostate by Trichomonas vaginalis is generally a late manifestation of the disease and is then almost always associated with symptoms. The development of epididymitis in a man suffering from non-gonococcal urethritis should cause a careful search to be made for Trichomonas vaginalis. 


\section{TRICHOMONAS VAGINALIS INFESTATION}

\section{REFERENCES}

Allen, E., Jensen, L. B. \& Wood, I. H. (I935) Amer. J. Obst. \& Gynec., 30, 565 .

Corneli, E. L. \& Riba, L. W. (I936) Surg. Gynec. Obstet., 63, 5 II.

Curtis, A. H. (I9I4) ibid. 18, 299.

DASTIDAR, S. K. G. (I925) Indian med. Gaz., 60, r6o.

Dock, G. (1896) Amer. J. med. Sci., 3, I.

Donné, A. (1836) Comp. rend. Acad. de Sci., 3, 385.

Drummond, A. C. (I936) Amer. J. Surg., 31, 98.

Grimm, O. (I930) Dermat. Ztschr., 59, 3 I4.

Hesseltine, H. C. (I933) Amer. J. Obstet. \& Gynec., 26, 46.

KaRnaky, K. J. (I938) Urol. \& Cutan. Rev., 42, 812.

Katsunuma, S. (I924) Bull. Soc. Path. exot., 17, 216.

Lewis, B. \& Carroll, G. (I928) J. Urol., 19, 337.

Liston, W. G. \& Liston, W. A. (I939) J. Obstet. Gynac., 46, 474.

Marchand, F. (I894) Centrabl. f. Bakt., 15, 709.

MIURA, K. (I894) ibid. 16, 67.

Nitschke, P. H. (1936) J. Amer. med. Assn., 10\%, I2.

RibA, L. W. \& Perry, E. (I929) J. Urol., 22, 563.

Rosenthal, D. B. (I93I) Med.J. Aust., 1, 782.

Stühler, L. G. (I933) Proc. Staff. Meet. Mayo Clinic, 8, 22 I.

Visher, J. W. (I929) J. Amer. med. Assn., 92, 2098. 